\title{
Is acupuncture effective in the treatment of pain in endometriosis?
}

\author{
Iréne Lund' \\ Thomas Lundeberg ${ }^{2}$ \\ 'Department of Physiology and \\ Pharmacology, Karolinska Institutet, \\ ${ }^{2}$ Rehabilitation Medicine University \\ Clinic Stockholm, Danderyds Hospital \\ AB, Stockholm, Sweden
}

This article was published in the following Dove Press journal: Journal of Pain Research

24 March 2016

Number of times this article has been viewed
Correspondence: Iréne Lund Department of Physiology and Pharmacology, Karolinska Institutet, von Eulers väg 8, SE I7I 77 Stockholm, Sweden Tel +46852487262

Email irene.lund@ki.se
Introduction: Endometriosis is a multifactorial, estrogen-dependent, inflammatory gynecological condition - often with long-lasting visceral pelvic pain of different origin, and infertility among women. Current management options for patients' are often inadequate, with side effects for many for whom acupuncture techniques could be an alternative. Earlier studies have discussed the efficacy of acupuncture, but not its methodological aspects.

Objectives: To summarize the documented clinical effects of acupuncture on rated visceral pelvic endometriosis-related pain, and associated variables among individuals, within and between studied groups, and to discuss the methodological treatment aspects.

Methods: Published full text clinical studies, case reports, and observational studies with abstracts written in English were searched by using the keywords "Acupuncture and Endometriosis" in databases such as PubMed, Web of Science, and CINAHL. The reporting guidelines, Standards for Reporting Interventions in Clinical Trials of Acupuncture was used for the methodological report.

Results: Three studies were found including 99 women, 13-40 years old, with diagnosed endometriosis. The studies were different in research design, needle stimulation techniques, and evaluation instruments. Methodological similarities were seven to 12 needle insertions per subject/session, and 15-25 minutes of needle retention time. The needles were placed in lower back/pelvic-abdominal area, in the shank, feet, and hands. Treatment numbers varied from nine to 16 and patients received one to two treatments per week. Similarity in reported treatment effects in the quoted studies, irrespective of research design or treatment technique, was reported decrease of rated pain intensity.

Discussion: Meta-analysis is the standard procedure for the evaluation of evidence of treatment effects, ie, on a group level, usually without analysis of the individual responses even with obvious spread in the results leading to lack of guidance for treatment of the individual patient. By conceptualizing pain as subjective, the individual aspect should serve as the basis for the analysis to allow clinical recommendations. From a physiological and a western medical perspective, acupuncture can be regarded as a type of sensory stimulation that induces changes in the function of the central nervous system that partly can explain the decrease of perceived pain in response to acupuncture treatment irrespective of the technique.

Conclusion: Endometriosis is often painful, although with various origin, where standard treatments may be insufficient or involve side effects. Based on the reported studies, acupuncture could be tried as a complement as it is an overall safe treatment. In the future, studies designed for evaluating effectiveness between treatment strategies rather than efficacy design would be preferred as the analyses of treatment effects in the individual patients.

Keywords: acupuncture, endometriosis, pelvic pain, pain treatment, STRICTA, individual responses 


\section{Introduction}

Endometriosis is described as a multifactorial, estrogendependent inflammatory gynecological condition that can result in long-lasting visceral pelvic pain and infertility. ${ }^{1,2}$ It can also be associated with irritable bowel syndrome and or interstitial cystitis/painful bladder syndrome. ${ }^{3}$ The condition is common worldwide, affecting approximately $5 \%-15 \%$ of women in reproductive age. ${ }^{4}$

One discussed possible mechanism for the onset of endometriosis is retrograded menstrual bleeding including endometrial tissue, often referred to as lesions, that is, manifested outside the uterus in diverse anatomical locations in the abdominal/pelvic cavity, ${ }^{5-7}$ and manifested as deep infiltrating endometriosis. ${ }^{8}$ An interactive and imbalanced function of sensory and autonomic nerve fibers innervating the extra-uterine lesions may maintain the endometriosis-related inflammatory process and one possible source of pain. ${ }^{8-11}$ Secondary ischemic reactions in local tissue and local nerve lesions (nerve distortion, compression, or damage) have also been discussed as the sources of the endometriosis-related pain. ${ }^{12,13}$ The pain, often long lasting, can be intermittent or continuous, appears as dysmenorrhea, dyspareunia, and/or dyschezia and, can be characterized as dull, throbbing, sharp, and burning, which sometimes is exacerbated by physical activity., ${ }^{3,14}$ Moreover, local muscular trigger points that are related to endometriosis can induce both local and referred pain which in turn results in lower pain thresholds in the painful area. ${ }^{15}$

The abnormal existence of the extra-uterine lesions is confirmed by diagnostic laparoscopy and frequently staged I-IV (ranging from I, indicating minimal disease, to IV, indicating severe disease) according to the American Society for Reproductive Medicine. ${ }^{16}$ The staging refers to the type, location, appearance, and depth of invasion of the lesions but is not always associated with the patients' perceived pain intensity or severity, and vice versa. ${ }^{1,8,9}$

The endometriosis related changes may be due to plastic changes in the peripheral and central nervous system that possibly predispose for other long-lasting pain conditions, ${ }^{3}$ therefore identifying pain alleviation strategies is of great importance. The present clinically offered therapies aim to alleviate pain by different mechanisms that often consist of various types of pharmacological and surgical treatments. However, many of these interventions do not affect the perceived pain sufficiently or there can be a relapse of pain, ${ }^{17-19}$ and sometimes the therapies come with considerable side effects. $^{20}$

Non-pharmacological treatment strategies based on sensory stimulation which includes different types of acupuncture, could serve as a complementary alternative. The pain-alleviating effects induced by acupuncture have been attributed to different physiological and psychological processes such as activation of endogenous descending pain inhibitory systems, deactivation of brain areas transmitting sensations of pain-related unpleasantness, interaction between nociceptive impulses and somato-visceral reflexes, and as a method that induces the expectation of symptom relief. ${ }^{21-23}$ Although acupuncture is widely used to manage long-term pain, ${ }^{24}$ it is still controversial. However, it has been described as a safe treatment method with very few reported serious side effects, provided that it is carried out by a skilled therapist, ${ }^{25,26}$ and a potent pain-alleviating treatment method for different long-term pain condition. ${ }^{27,28}$ Its pain-alleviating effects in comparison with various controlled conditions were reported by MacPherson et al, ${ }^{29}$ but they have been questioned by others. ${ }^{30}$ Earlier overviews, based on studies with a randomized clinical trial design, have discussed the reported clinical pain alleviating effects of acupuncture on endometriosis pain as limite $\mathrm{d}^{31,32}$ and suggest that future studies preferably should be properly randomized and double-blinded..$^{31}$ To get an overall picture of what is clinically known within the field, it would be beneficial to analyze studies with different design types, even though they are not double-blinded as double-blinding studies with acupuncture or having accurate placebo controls are a great challenge..$^{33,34}$

Ideally, treatment should be individually tailor based, ${ }^{35-37}$ that is, based on the individual's specific symptoms and needs as pain is perceived differently in different individuals, and the same type of symptom may have different implications for different women. ${ }^{2}$ Consequently, to increase the understanding of a patient's level of pain and as a base for clinical decisions about treatment, it would be of interest to evaluate both the individual responses of those participating in a study, as well as the responses of the entire study group.

This work aims to summarize documented effects of acupuncture, applied with different techniques, on rated visceral pelvic endometriosis-related pain and associated variables among individuals as well as within and between studied groups. Also, methodological aspects of the treatment that may influence the results will be discussed.

\section{Methods}

This paper is a literature review of documented clinical studies evaluating acupuncture effects on endometriosis-related pelvic pain. The inclusion criteria were full text articles of clinical trials, case reports, and observational studies with 
abstracts written in English. The available literature was found using the keywords "Acupuncture AND Endometriosis" in the databases such as PubMed, Web of Science, and CINAHL.

The methodological aspects of the acupuncture treatment in the criteria met articles were in this review reported according to STandards for Reporting Interventions in Clinical Trials of Acupuncture (STRICTA). ${ }^{38}$ STRICTA is a reporting guideline that is primarily designed to improve the completeness and transparency of reporting in clinical trials of acupuncture. The guideline is conducted in agreement between the STRICTA group and the Consolidated Standards of Reporting Trials group in collaboration with the Chinese Cochrane Centre, and the Chinese Centre for Evidence-based Medicine.

\section{Results}

The search resulted in a total of five articles published between 2006 and 2010. ${ }^{39-43}$ Two of the five articles were excluded since one of them ${ }^{42}$ reported developed methodological discussions applied to the same material as one of the other included articles, and the other article excluded ${ }^{40}$ was written as an explanatory protocol for Japanese acupuncture technique. Consequently, three articles were included in the present overview. . $^{39,41,43}$

\section{Research design, outcome variables, and patients' data}

Two of the studies ${ }^{41,43}$ were performed using a prospective randomized, single-blind placebo/sham design, with one of them also having a crossover design..$^{43}$ The third study ${ }^{39}$ was a retrospective observational case series study based on the history of two adolescent girls with endometriosis and severe pelvic pain treated with acupuncture.

In total 121 women, 13-40 years old, with diagnosed endometriosis stage I-IV according to the American Society for Reproductive Medicine, were included in the studies for acupuncture treatment of their endometriosis-related pain (Table 1).

In all three studies, the patient-rated pain intensity was the primary outcome variable, although evaluated with the use of different uni-dimensional rating scales (Visual Analog Scale, Numeric Rating Scale, and Verbal Rating Scale). In two of the studies, patients pain intensity was rated on the scale's upper half $\mathrm{f}^{39,43}$ before the start of the treatment, while the patients' pain intensity ratings, in the study by Wayne et $\mathrm{al}^{41}$ was spread from the lower part of the scale to its upper. The women also rated their health-related quality of life (HRQOL) in two of the studies ${ }^{41,43}$ with different multidimensional instruments (SF-36, Endometriosis Health Profile-30, and The Paediatric Quality of Life Inventory). Additional outcome variables in the study of Rubi-Klein et $a{ }^{43}$ were rated pain disability, patients' treatment expectation, take home baby rate, number of absent days, and analgesic intakes. Wayne et $\mathrm{al}^{41}$ additionally asked their patients to rate their perceived symptom severity by their perceived stress. Also, the presence of serum inflammatory markers was measured in the same study. In the retrospective case series study by Highfield et al, ${ }^{39}$ the two adolescent girls also responded to questions on the symptom of the greatest concern, eg, fatigue, constipation, medication, and attendance at school. Description of assessment instruments and timepoint for assessment are described in Table 1.

\section{Methodological aspects on acupuncture according to STRICTA}

Methodological aspects of the treatment procedures that are described by items in the checklist according to STRICTA are presented in Table 2. Two of the studies used acupuncture techniques based on traditional Chinese medicine and Japanese acupuncture technique, all individually tailor based on the patient's symptoms.

The selection of acupuncture points varied between the studies, but they were in summary anatomically located in the lower back/pelvic region, in the lower abdominal area, and also in the hands and feet. The points were intra segmentally related to visceral organ innervation. One of the studies ${ }^{41}$ also described the additional use of auricular acupuncture points.

Stimulation depth in the three studies varied from being intracutaneous and subcutaneous to being intramuscular. The stimulation was mainly manual but with different intensity characterized by a needle sensation, deQi, in the studies of Highfield et $\mathrm{al}^{39}$ and Rubi-Klein et al, ${ }^{43}$ while a sensation described as weaker or more gentle than the deQi sensation and characterized as an "echo" in the therapist's hand was sought for in the study by Wayne et al. ${ }^{41}$ Moxa applied on the needles were described in all three studies as a possibility when regarded as appropriate.

The needle insertions per subject and treatment session were 7-12, and the needle retention time described as 15-20 minutes. The number of treatments varied from 9 to 16 among the three studies and the treatment frequency was presented as twice a week in works by Wayne et $\mathrm{al}^{41}$ and Rubi-Klein et al, ${ }^{43}$ while Highfield et $\mathrm{al}^{39}$ described that as in average a little bit more than once a week. Continuation with the regular analgesic intervention was reported in two of the studies. ${ }^{39,43}$ 
Table I Data of included subjects, diagnosis, study design, outcome variables, assessment time point, and instrument

\begin{tabular}{|c|c|c|c|}
\hline & \multicolumn{3}{|l|}{ Included studies } \\
\hline & Rubi-Klein et al ${ }^{43}$ & Wayne et $\mathrm{al}^{41}$ & Highfield et $\mathrm{a}^{39}$ \\
\hline $\begin{array}{l}\text { Number of patients } \\
\text { and age }\end{array}$ & $101,20-40$ years & $18,13-22$ years & $\begin{array}{l}\text { Two adolescent, one } \\
17 \text { years }\end{array}$ \\
\hline $\begin{array}{l}\text { Diagnose - laparoscopy } \\
\text { stage I-IV, ASRM }\end{array}$ & Stage II-IV & Stage I-III & Stage I \\
\hline Study design & $\begin{array}{l}\text { Prospective randomized single-blind, } \\
\text { placebo controlled, crossover week } 2 \\
\text { menstrual cycles between } 2 \text { treatment } \\
\text { units }\end{array}$ & $\begin{array}{l}\text { Prospective randomized single-blind, sham } \\
\text { controlled }\end{array}$ & $\begin{array}{l}\text { Retrospective case } \\
\text { series study }\end{array}$ \\
\hline $\begin{array}{l}\text { Rated pain intensity } \\
\text { at start }\end{array}$ & $\begin{array}{l}>5 \text {, VAS (no pain-worst possible } \\
\text { pain, 0-10) }\end{array}$ & 2-8 NRS (no pain-worst possible pain, 0-10) & $\begin{array}{l}\text { 5-8 NRS (no pain-worst } \\
\text { possible pain, } 0-10 \text { ) }\end{array}$ \\
\hline Outcome variable & $\begin{array}{l}\text { Rated pain intensity, pain disability, } \\
\text { HRQOL, treatment expectation (high, } \\
\text { intermediate, and low); absentee days; } \\
\text { take home baby rate; analgesic intake }\end{array}$ & $\begin{array}{l}\text { Rated pain intensity, (actual and during the past } \\
4 \text { weeks), HRQOL, perceived stress; measured } \\
\text { serum inflammatory markers }\end{array}$ & $\begin{array}{l}\text { Rated pain intensity, } \\
\text { symptom of greatest } \\
\text { concern, eg, fatigue, } \\
\text { constipation, medication, } \\
\text { attendance at school }\end{array}$ \\
\hline $\begin{array}{l}\text { Assessment per variable } \\
\text { a. Time point } \\
\text { b. Instrument }\end{array}$ & $\begin{array}{l}\text { Pain intensity: } \\
\text { a. Before, after each unit (evaluated } \\
4 \text { times) } \\
\text { b. VAS (see "Rated pain intensity at } \\
\text { start"), VRS (no-slight-average-severe) } \\
\text { Pain disability: } \\
\text { a. Before, after the study (twice) } \\
\text { b. PDI } \\
\text { HRQOL: } \\
\text { a. Before, after each unit (4 times) } \\
\text { b. SF-36 } \\
\text { Analgesic intake: } \\
\text { a. Daily } \\
\text { b. Diary } \\
\text { Treatment expectation: } \\
\text { a. Before } \\
\text { Number of absentee days: } \\
\text { a. Before, after study, } 6 \text { months follow-up } \\
\text { b. - } \\
\text { Take home baby rate: } \\
\text { a. Before, after study, } 6 \text { months follow-up } \\
\text { b. - }\end{array}$ & $\begin{array}{l}\text { Pain intensity: } \\
\text { a. Before } 4 \text { weeks, } 8 \text { weeks, } 6 \text { months following } \\
\text { start of treatment } \\
\text { b. NRS (no pain-worst possible pain, 0-10) } \\
\text { Symptom severity: } \\
\text { a. Before, } 4 \text { weeks, } 8 \text { weeks, } 6 \text { months following } \\
\text { start of treatment } \\
\text { b. The Endometriosis Symptom Severity scale } \\
\text { HRQOL: } \\
\text { a. Before, } 4 \text { weeks, } 8 \text { weeks, } 6 \text { months following } \\
\text { start of treatment } \\
\text { b. Endometriosis Health Profile-30; The Paediatric } \\
\text { Quality of Life Inventory; The Perceived Stress } \\
\text { Scale; participant-generated list of } \\
\text { three activities made difficult due to pelvic pain } \\
\text { Serum inflammatory markers: } \\
\text { a. Before, } 4 \text { weeks, } 8 \text { weeks, } 6 \text { months following } \\
\text { start of treatment } \\
\text { b. IL-6, TNF- } \alpha\end{array}$ & $\begin{array}{l}\text { Pain intensity: } \\
\text { a. Before, after } \\
\text { treatment } \\
\text { b. NRS (no pain-worst } \\
\text { possible pain, 0-10) }\end{array}$ \\
\hline
\end{tabular}

Notes: The Endometriosis Symptom Severity scale instrument required - dysmenorrhea, dyspareunia, and non-menstrual pain is rated with VRS (absent, mild, moderate, and severe); Endometriosis Health Profile-30, 30 rated items divided in five subscales (pain, control/powerlessness, emotional wellbeing, social support, and self image) were each is rated with VAS (best possible health status to worst possible health status, 0-100); The Paediatric Quality of Life Inventory, 23-item multidimensional instrument rated with VRSs (never a problem; almost never a problem; sometimes a problem; often a problem; almost always a problem) divided into four domains (physical functioning, emotional functioning, social functioning, and school functioning); The Perceived Stress Scale, A I0-item instrument each scored from "not at all" to "very much" (0-4); A participantgenerated list of three activities made difficult due to pelvic pain rated with NRS, not difficult-most difficult (0-10). PDI is to what degree pain disables seven aspects of life are disrupted by chronic pain rated by NRS (no disability-worst disability, 0-10) family/home responsibilities, recreation, social activity, occupation, sexual behavior, self care, and life-support activities. The SF36 is to what extent 36 rated items, based on different number of VRSs, grouped into vitality, physical functioning, bodily pain, general health perceptions, physical role functioning, emotional role functioning, social role functioning, and mental health are affected by the pain.

Abbreviations: ASRM, American Society for Reproductive Medicine; HRQOL, health-related quality of life; IL, interleukin; NRS, Numeric Rating Scale; PDI, Pain Disability Index; TNF- $\alpha$, tumor necrosis factor alpha; VAS, Visual Analog Scale; VRS, Verbal Rating Scale.

Two of the three studies were aimed to evaluate the efficacy of acupuncture as compared to a control group. As a control method, Rubi-Klein et al ${ }^{43}$ used non-specific acupuncture points (ie, well-defined acupuncture points according to traditional Chinese medicine principles are unrelated to endometriosis) that in this case were located on the head, shoulder, chest, and thigh. The non-specific acupuncture points were stimulated less, described as a constant subcutaneous neutral needling technique, as compared to the "real" acupuncture technique where a needling sensation often in intramuscular tissue was sought for. This study also had a crossover design, meaning that the groups changed the type of treatment. Wayne et a ${ }^{41}$ used the non-penetrating Streitberger needles as a control treatment where these needles were 


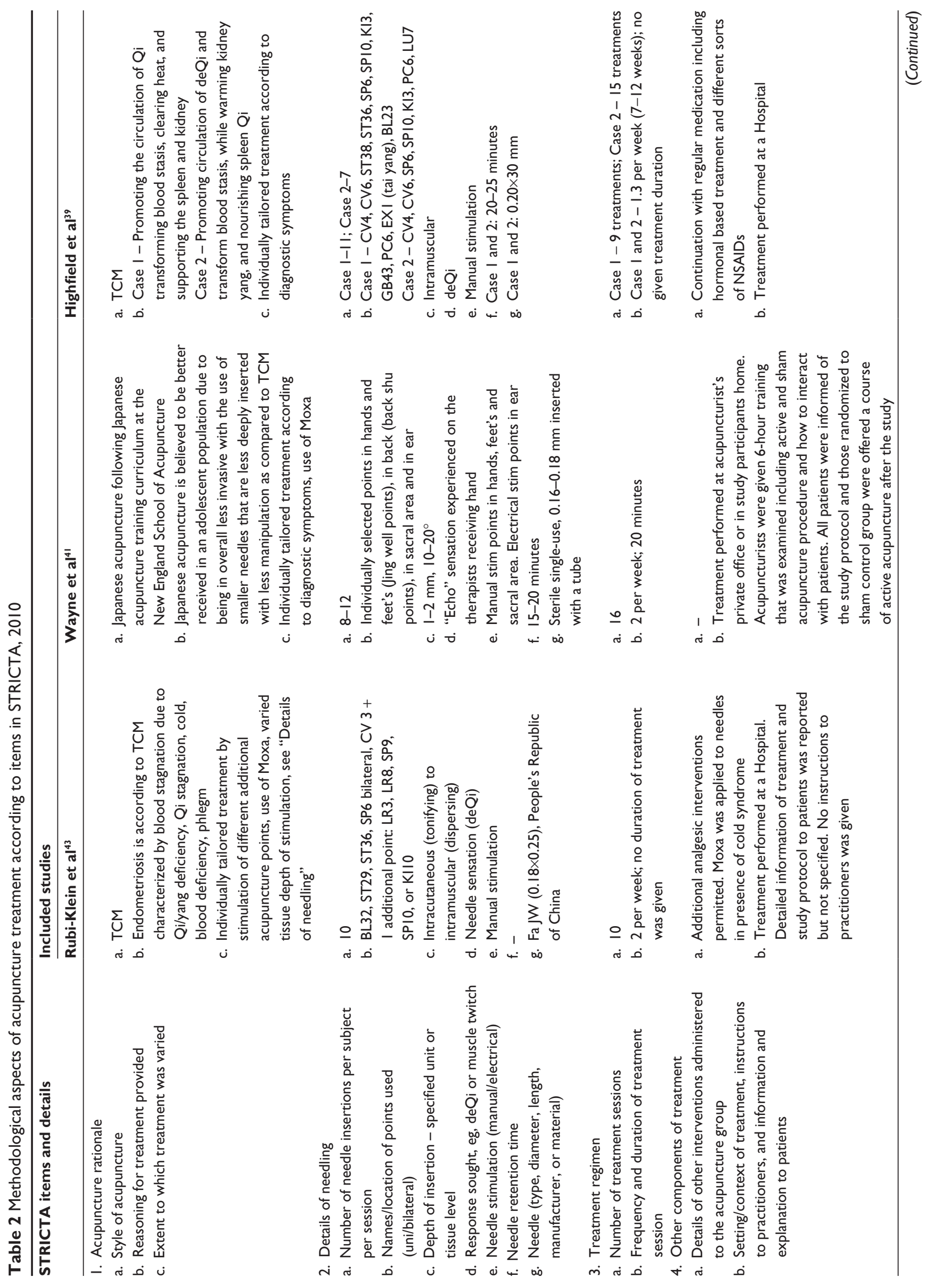




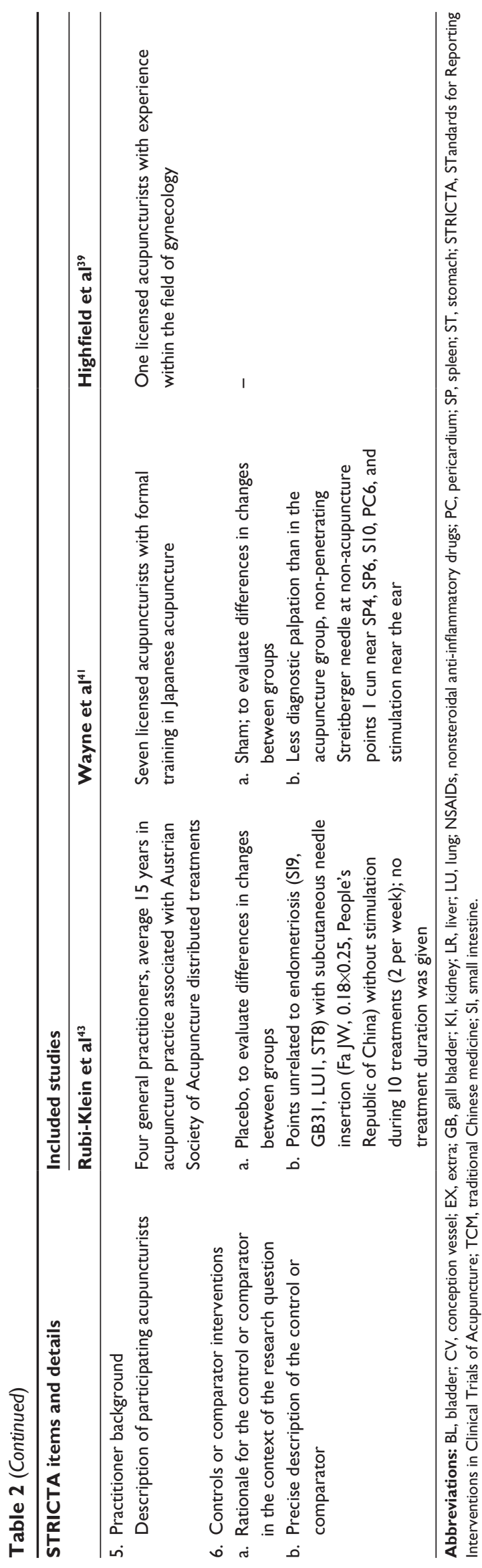

attached to the skin over non-acupuncture points close to ( $1 \mathrm{~cm}$ away) defined acupuncture points in the forearm, shank, and foot. The treatments were performed at a hospital, ${ }^{39,43}$ in the acupuncturist's office, or in the patient's home..$^{41}$

\section{Reported treatment results}

The first two studies ${ }^{41,43}$ reported a dropout among their patients, 18 and four patients respectively, resulting in a total of 99 women who were included in the analysis of treatment effects, as shown in Table 3.

\section{Within group effects}

In all three studies, ${ }^{39,41,43}$ the patients rated their pain intensity lower after acupuncture treatment, regardless of the acupuncture technique, as compared to before the start of the treatment period. Another aspect of pain evaluation, rated pain disability, used by Rubi-Klein et $\mathrm{a}^{43}$ was rated lower after treatment.

Also, the treated patient rated their HRQOL higher in two of studies. Decrease of analgesic intake and perceived stress within the acupuncture-treated groups were reported in the studies of Rubi-Klein et $\mathrm{al}^{43}$ and Wayne et $\mathrm{al},{ }^{41}$ respectively. In the observational study by Highfield et al, ${ }^{39}$ the social activity and attendance in school activity were reported as increased after the treatment period.

\section{Between group effects}

Systematic differences between the treatment group and the control group in the evaluation of rated pain intensity and the HRQOL subgroups "social efficiency" and "psychological well-being" were demonstrated in the Rubi-Klein et al study. ${ }^{43}$ A long-lasting effect of acupuncture on perceived pain in the same study made it difficult to interpret the effect of control treatment after being giving the "real" acupuncture.

In the study by Wayne et al, ${ }^{41}$ there were also some effects reported but there was not enough evidence to establish systematic differences between the groups in any of the used outcome variables.

\section{Discussion}

This review is based on the results of evaluating three studies $^{39,41,43}$ treatment effects of acupuncture, performed with different techniques, on rated endometriosis-related pelvic pain and associated variables. The studies also comprised of different study design and different number of patients included; two of the studies had a small number of patients, and a different number of evaluation instruments. 
Table 3 Described results on rated pain, health-related quality of life, and additional endometriosis-related variables in the evaluated studies

\begin{tabular}{|c|c|c|c|}
\hline \multirow{2}{*}{$\begin{array}{l}\text { Outcome variables, type } \\
\text { of comparisons of change } \\
\text { before-after treatment }\end{array}$} & \multicolumn{3}{|c|}{ Included studies, number of included patients in analysis } \\
\hline & Rubi-Klein et al, ${ }^{43} \mathrm{n}=83$ & Wayne et al, ${ }^{41} n=14$ & Highfield et $\mathrm{al}^{39} \mathrm{n}=2$ \\
\hline \multicolumn{4}{|l|}{ Rated pain intensity } \\
\hline $\begin{array}{l}\text { Within groups } \\
\text { Between groups }\end{array}$ & $\begin{array}{l}\text { Ratings at the lower half of the scale in the } \\
\text { acupuncture group unchanged in placebo group } \\
\text { Lower levels in acupuncture group as compared } \\
\text { to placebo group }\end{array}$ & $\begin{array}{l}\text { Ratings at the lower half of the } \\
\text { scale in both groups } \\
\text { No differences between the groups }\end{array}$ & $\begin{array}{l}\text { Decreased rating in both } \\
\text { patients }\end{array}$ \\
\hline \multicolumn{4}{|l|}{ Rated pain disability } \\
\hline $\begin{array}{l}\text { Within groups } \\
\text { Between groups }\end{array}$ & $\begin{array}{l}\text { Lower rated levels in both groups } \\
\text { No difference when compared after crossover }\end{array}$ & - & - \\
\hline $\begin{array}{l}\text { Within groups } \\
\text { Between groups }\end{array}$ & $\begin{array}{l}\text { Increased in seven of eight items of } \\
\text { SF } 36 \text { in both groups } \\
\text { Social efficiency, psychological wellbeing higher } \\
\text { in acupuncture group than in placebo group }\end{array}$ & $\begin{array}{l}\text { Increased in acupuncture group } \\
\text { No differences }\end{array}$ & - \\
\hline Additional variables & $\begin{array}{l}\text { Take home baby rate: } 5 \text { ( } 5 \text { of } 7 \text { ) women } \\
\text { pregnant women ended their pregnancy } \\
\text { successful (group allocation unspecified) } \\
\text { Absentee days: decrease in both groups } \\
\text { Analgesic intake: decrease in acupuncture group } \\
\text { Treatment expectation: rated higher } \\
\text { expectation led to more marked decrease of } \\
\text { pain intensity (group allocation unspecified) }\end{array}$ & $\begin{array}{l}\text { Perceived stress: decrease in } \\
\text { both groups } \\
\text { Inflammatory markers (IL-6, } \\
\text { TNF } \alpha \text { ): no within group or } \\
\text { between group differences }\end{array}$ & $\begin{array}{l}\text { Social activity and } \\
\text { attendance in school activity: } \\
\text { increased in both patients }\end{array}$ \\
\hline
\end{tabular}

Abbreviations: HRQOL, health-related quality of life; SF36, short form (36); IL, interleukin; TNF- $\alpha$, tumor necrosis factor $\alpha$.

In all three studies, ${ }^{39,41,43}$ within-group effects of rated pain intensity was demonstrated to be at lower levels after treatment than before the start of treatment. In two of them, there were also reported effects on rated HRQOL at a higher level after treatment than before.

In the two studies ${ }^{41,43}$ that were aimed to test the treatment efficacy by comparing the results from a group treated with acupuncture with a group treated with what was labeled as placebo, one showed systematic effects between the groups with advantage for the use of acupuncture ${ }^{43}$ while there was not enough evidence in the other, with a smaller number of patients. ${ }^{41}$

From a physiological and a western medical perspective, acupuncture can be regarded as a type of sensory stimulation that induces changes in the function of the central nervous system, which can partly explain the decrease of perceived pain in response to acupuncture treatment. Except for the needle stimulation, acupuncture also includes an inevitable tactile stimulation of the patient during the treatment that is also present when inserting needles subcutaneously into sites not related to endometriosis pain and even when attaching the Streitberger needle. Therefore, it is still not possible to present a valid inert placebo control for adequate comparisons between groups since all types of hitherto present placebo models comprise some kind of afferent nerve activity. ${ }^{33}$ Consequently, perhaps the applied placebo controls used in the present studies could physiologically be regarded as types of acupuncture stimulation.

Despite differences between the studies, there were also similarities that the acupuncture points were located in the lower back/pelvic and abdominal area, in the shank, feet, and hands, and the points were stimulated for 15-25 minutes per treatment. The treatment sessions were repeated for 9-16 times with a frequency of 1-2 times/week. Another interesting and valuable aspect is that there were no reported side effects in any of the studies.

This could indicate that different acupuncture stimulation techniques, shallow or more intense, with needles inserted superficially or more deeply, may alleviate pain and increase in quality of life in women with endometriosis-related pelvic pain. Current literature however, gives no support to determine what type of acupuncture stimulation is the most effective. On the other hand, maybe all mentioned types could be available in clinical decisions as complementary pain-alleviating treatment depending on what is the best choice for the individual patient. According to the principles of evidence-based medicine, there is a need for practical aspects to be included to find a firm basis for clinical decisions aside from 'hard evidence' relating to what is found in groups of patients. ${ }^{44}$ 
Summarized data from many studies are often included in meta-analysis with the aim of describing the different study effect sizes and are standard procedure for the evaluation of evidence on a group level. However, one shortcoming is that the individual responses are usually not analyzed even with obvious spread in the results leading to a lack of guidance for the treatment of the individual. The conceptualizing of pain as a subjective experience leads to the need to find other methods of determining clinical effects than those relying on group-derived comparisons that apply uniform standards to all patients. ${ }^{36}$ Moreover, all results from therapies effect size obtained from meta-analysis is not interpretable when the studies' evaluation instruments are based on the patients' subjective experience of pain, for example Vickers et al ${ }^{27}$ presented a recalculated metaanalysis where the individual aspects were considered, and they concluded that acupuncture can be regarded as having potential effects in different long-term pain conditions. As severe endometriosis-related pain can be related to different possible causes, such as inflammatory or neuropathic, it also needs to be taken into consideration the evaluation of treatment effects. ${ }^{45}$

\section{Limitations}

This review includes articles written in the English language, which was a base for evaluation of the articles, but can perhaps be seen as a limitation of the number of articles included. The commented studies in this report have a limited number of patients making patterns of changes even more variable than if they had included a larger number of patients. In order to strengthen decision making for clinical treatment, it would therefore be desirable that a larger number of patients were included in future studies. Also, in future studies it would be desirable to make comparisons between different treatment strategies that are probably more accurate, and to perform individual analyses.

\section{Conclusion}

Endometriosis is often presented with severe pain of various genesis, where the different usual/standard treatment forms may be inadequate or involve side effects. Based on the analysis in the presented review, there are grounds to believe that acupuncture can relieve pain in some patients. The effects of acupuncture as a pain-relieving treatment has in various studies been presented as an overall safe alternative treatment with very few and small (harmless) side effects, and furthermore with no effect on the environment. It could therefore also be regarded as a 'sustainable' treatment. In the future, studies designed for evaluating effectiveness between different types of treatment strategies, rather than efficacy design would be preferred to analyze treatment effects in individual patients.

\section{Disclosure}

The authors report no conflicts of interest in this work.

\section{References}

1. Vercellini P, Fedele L, Aimi G, Pietropaolo G, Consonni D, Crosignani PG. Association between endometriosis stage, lesion type, patient characteristics and severity of pelvic pain symptoms: a multivariate analysis of over 1000 patients. Hum Reprod. 2007;22(1):266-271.

2. Vercellini P, Viganò P, Somigliana E, Fedele L. Endometriosis: pathogenesis and treatment. Nat Rev Endocrinol. 2014;10(5): 261-275.

3. Brawn J, Morotti M, Zondervan KT, Becker CM, Vincent K. Central changes associated with chronic pelvic pain and endometriosis. Hum Reprod Update. 2014;20(5):737-747.

4. Viganò P, Parazzini F, Somigliana E, Vercellini P. Endometriosis: epidemiology and aetilogical factors. Best Pract Res Clin Obstet Gynaecol. 2004;18(2):177-200.

5. Fauconnier A, Chapron C. Endometriosis and pelvic pain: epidemiological evidence of the relationship and implications. Hum Reprod Update. 2005;11(6):595-606.

6. Farquhar C. Endometriosis. BMJ. 2007;334(7587):249-253.

7. Huntington A, Gilmour JA. A life shaped by pain: women and endometriosis. J Clin Nurs. 2005;14(9):1124-1132.

8. Guidice, LC. Endometriosis. N Engl J Med. 2010;362(25):2389-2398.

9. Wang G, Tokushige N, Markham R, Fraser IS. Rich innervation of deep infiltrating endometriosis. Hum Reprod. 2009;24(4):827-834.

10. Arnold J, Barcena de Arellaon ML, Rüster C, et al. Imbalance between sympathetic and sensory innervation in peritoneal endometriosis. Brain Behav Immun. 2012;26(1):132-141.

11. McKinnon BD, Bertschi D, Bersinger NA, Mueller MD. Inflammation and nerve fiber interaction in endometriotic pain. Trends Endocrinol Metab. 2015;26(1):1-10.

12. Anaf V, Simon P, El Nakadi I, et al. Hyperalgesia, nerve infiltration and nerve growth factor expression in deep adenomyotic nodules, peritoneal and ovarian endometriosis. Hum Reprod. 2002;17(7):1895-1900.

13. Anaf V, Chapron C, El Nakadi I, De Moor V, Simonart T, Noel JC. Pain, mast cells, and nerves in peritoneal, ovarian, and deep infiltrating endometriosis. Fertil Steril. 2006;86(5):1336-1343.

14. Bajaj P, Bajaj P, Madsen H, Arendt-Nielsen L. Endometriosis is associated with central sensitization: a psychophysical controlled study. J Pain. 2003;4(7):372-380.

15. Stratton P, Khachikyan I, Sinaii N, Ortiz R, Shah J. Association of chronic pelvic pain and endometriosis with signs of sensitization and myofascial pain. Obstet Gynecol. 2015;125(3):719-728.

16. Practice Committee of the American Society for Reproductive Medicine. Endometriosis and infertility. Fertil Steril. 2006;86(5 Suppl 1): S156-S160.

17. Eisermann J, Gast MJ, Pineda J, Odem RR, Collins JL. Tumor necrosis factor in peritoneal fluid of women undergoing laparoscopic surgery. Fertil Steril. 1988;50(4):573-579.

18. Abbott JA, Hawe J, Clayton RD, Garry R. The effects and effectiveness of laparoscopic excision of endometriosis: a prospective study with 2-5 year follow-up. Hum Reprod. 2003;18(9):1922-1927.

19. Fedele L, Bianchi S, Zanconato G, Bettoni G, Gotsch F. Long-term follow-up after conservative surgery for rectovaginal endometriosis. Am J Obstet Gynecol. 2004;190(4):1020-1024.

20. Wieser F, Cohen M, Gaeddert A, et al. Evolution of medical treatment for endometriosis: back to the roots? Hum Reprod Update. 2007;13(5):487-499. 
21. Andersson S, Lundeberg T. Acupuncture - from empiricism to science: functional background to acupuncture effects in pain and disease. Med Hypotheses. 1995;45(3):271-281.

22. Hui KK, Liu J, Marina O, et al. The integrated response of the human cerebro-cerebellar and limbic systems to acupuncture stimulation at ST 36 as evidenced by fMRI. Neuroimage. 2005;27(3):479-496.

23. Chen S, Wang S, Rong P, et al. Acupuncture for visceral pain: neural substrates and potential mechanisms. Evid Based Complement Alternat Med. 2014;2014:609594.

24. Chon TY, Lee MC. Acupuncture. Mayo Clin Proc. 2013;88(10): 1141-1146.

25. MacPherson H, Thomas K, Walters S, Fitter M. The York acupuncture safety study: prospective survey of 34000 treatments by traditional acupuncturists. BMJ. 2001;323(7311):486-487.

26. White A. A cumulative review of the range and incidence of significant adverse events associated with acupuncture. Acupunct Med. 2004; 22(3):122-133.

27. Vickers AJ, Cronin AM, Maschino AC, et al. Acupuncture Trialists' Collaboration. Acupuncture for chronic pain. Arch Intern Med. 2012; 172(19):1444-1453.

28. Vickers AJ, Linde K. Acupuncture for chronic pain. JAMA. 2014; 311(9):955-956.

29. MacPherson H, Vertosick E, Lewith G, et al. Influence of control group on effect size in trials of acupuncture for chronic pain: a secondary analysis of an individual patient data meta-analysis. PLoS One. 2014;9(4):e93739.

30. Madsen MV, Gøtzsche PC, Hróbjartsson A. Acupuncture treatment for pain: systematic review of randomised clinical trials with acupuncture, placebo acupuncture, and no acupuncture groups. BMJ. 2009;338:a3115.

31. Zhu X, Hamilton KD, McNicol ED. Acupuncture for pain in endometriosis. Cochrane Database Syst Rev. 2011;9:CD007864.

32. Kong S, Zhang YH, Liu CF, et al. The complementary and alternative medicine for endometriosis: a review of utilization and mechanism. Evid Based Complement Alternat Med. 2014;2014:146383.

33. Lund I, Lundeberg T. Are minimal, superficial or sham acupuncture procedures acceptable as inert placebo controls? Acupunct Med. 2006; 24(1):13-15.
34. Lundeberg T, Lund I, Sing A, Näslund J. Is placebo acupuncture what it is intended to be? Evid Based Complement Alternat Med. 2011;2011: 932407.

35. Lund I, Lundeberg T. Aspects of pain, its assessment and evaluation from an acupuncture perspective. Acupunct Med. 2006;24(3):109-117.

36. Birnie KA, McGrath PJ, Chambers CT. When does pain matter? Acknowledging the subjectivity of clinical significance. Pain. 2012; 153(12):2311-2314.

37. Moore RA, Derry S, Wiffen PJ. Challenges in design and interpretation of chronic pain trials. Br J Anaesth. 2013;111(1):38-45.

38. MacPherson H, Altman DG, Hammerschlag R, et al. STRICTA Revision Group. Revised STandards for Reporting Interventions in Clinical Trials of Acupuncture (STRICTA): extending the CONSORT statement. PLoS Med. 2010;7:e1000261.

39. Highfield ES, Laufer MR, Schnyer RN, Kerr CE, Thomas P, Wayne PM. Adolescent: endometriosis-related pelvic pain treated with acupuncture; two case reports. J Altern Complement Med. 2006;12(3):317-322.

40. Schnyer RN, Iuliano D, Kay J, Shields M, Wayne P. Development of protocols for randomized sham-controlled trials of complex treatment interventions: Japanese acupuncture for endometriosis-related pelvic pain. J Altern Complement Med. 2008;14(5):515-522.

41. Wayne PM, Kerr CE, Schneyer RN, et al. Japanese-style acupuncture for endometriosis-related pelvic apin in adolescents and young women: results of a randomized sham-controlled trial. J Pediatr Adolesc Gynecol. 2008;21(5):247-257.

42. Ahn AC, Schnyer R, Conboy L, Laufer MR, Wayne PM. Electrodermal measures of Jing-Well points and their clinical relevance in endometriosis-related chronic pelvic pain. J Altern Complement Med. 2009;15(12):1293-1305.

43. Rubi-Klein K, Kucera-Sliutz E, Nissel H, et al. Is acupuncture in addition to conventional medicine effective as pain treatment for endometriosis? A randomised controlled cross-over trial. Eur J Obstet Gynecol Reprod Biol. 2010;153(1):90-93.

44. Sackett DL, Rosenberg WM, Gray JA, Haynes RB, Richardson WS Evidence based medicine: what it is and what it isn't. BMJ. 1996 312(7023):71-72.

45. Lundeberg T, Lund I. Is there a role for acupuncture in endometriosis pain, or 'endometrialgia'? Acupunct Med. 2008;26(2):94-110.
Journal of Pain Research

\section{Publish your work in this journal}

The Journal of Pain Research is an international, peer-reviewed, open access, online journal that welcomes laboratory and clinical findings in the fields of pain research and the prevention and management of pain. Original research, reviews, symposium reports, hypothesis formation and commentaries are all considered for publication.

\section{Dovepress}

The manuscript management system is completely online and includes a very quick and fair peer-review system, which is all easy to use. Visit http://www.dovepress.com/testimonials.php to read real quotes from published authors. 